\title{
Modeling and control of two five-phase induction machines connected in series powered by matrix converter
}

\author{
Mohamed Nekkaz, Abdelkader Djahbar, Rachid Taleb \\ Laboratoire Génie Electrique et Energies Renouvelables (LGEER), Electrical Engineering Department, Hassiba \\ Benbouali University of Chlef, Algeria
}

\begin{tabular}{l} 
Article Info \\
\hline Article history: \\
Received Dec 6, 2019 \\
Revised Apr 27, 2021 \\
Accepted May 2, 2021 \\
\hline
\end{tabular}

Keywords:

Five-phase induction motor Five-phase matrix converter Multi machines system Vector control

\begin{abstract}
The two five-phase Induction Motor (IM) drive system that is serially connected is available in literature. The power supply of such system is considered as a matrix converter (a direct AC to AC converter system) by three and five-phases outputs. The main benefit from the drive topology is the sinusoidal source as a side current with a controllable input side power factor. The decoupled control is achieved similarly to the inverter based drive system. In this paper; the decoupled control of two five-phase induction machines serially connected and powered by a five-phase matrix converter as well as analytical and simulation results are presented.
\end{abstract}

This is an open access article under the $\underline{C C B Y-S A}$ license.

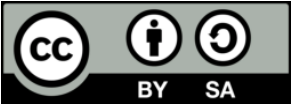

\section{Corresponding Author:}

Mohamed Nekkaz

Electrical Engineering Department

Hassiba Benbouali University of Chlef

Laboratoire Génie Electrique et Energies Renouvelables (LGEER)

BP. 78C, Ouled Fares 02180, Chlef, Algeria

Email: nekkaz_mohamed@yahoo.fr

\section{INTRODUCTION}

The three-phase induction machines are reported to have eminent recognized benefits including low maintenance, reliability, simple construction, ruggedness, off-shelf availability as well as cheaper cost which explain their widespread applications in numerous industries [1]. Furthermore, with the appearance of fast and cheap power electronic switching gadgets, the control of induction machines became flexible and easier in addition to the number of its phases that can be considered as a designed parameter that might be diverse.

The multi-phase motors (superior to three-phase) were extensively researched in literature. It has been found that they have multiple benefits compared to three-phase machines, for instance, reduced torque pulsations [2], [3], high density of torque [4], [5], stability and fault tolerance [6], [7] along low ripple current [8]. Therefore, multi-phase order machines are usually appraised for niche application areas like electric/hybrid electric vehicles, ship propulsion, robotics and electric aircraft. Exhausted reviews on the research development of multi-phase motors are proposed in $[9,10]$.

One of the applications of multi-phase machines is their parallel connection and/or series connection. This drive system is called a series-connected/parallel-connected two-motor drive system. This drive system is allocated from a variable frequency and variable voltage supply (most commonly a power electronic inverter) introduced in [11], [12]. The drive system is such that the motors are controlled independently and can carry different loads, can run at different speeds without interfering with each other. 
The type of machines applied in the drive topology is also not specific [13]. The machines are controlled using the vector control approach.

Considering that the vector controls of multi-phase motors need two stator current components thus, the additional stator current component is applied to control additional motors [14]. So, by connecting in series the multi-phase stator windings it will be possible to independently control every machine with supply appearing as an individual multi-phase voltage source inverter [15]. A particular drive system that is immersed by this concept is the parallel-connected/five-phase series two-motor drive, comprising the two five-phase motors and provided by an individual five-phase voltage source inverter. This topology was analyzed in substantial detail in [16], [17]. The multi-motor drive systems are disputed up to the present in the literature with the use of their supply of multi-phase voltage source inverter; however, the matrix converter was not tested for the drive of such topology.

This present paper deals with the feasibility of driving a five-phase series-connected two-motor drive system with a direct AC to AC converter (matrix converter) [18]. The originality of this work lies in the new solution of using a matrix converter for feeding two-motor drive topology by using modulation that produces two significant frequency outputs from the matrix converter in order to control the two seriesconnected five-phase motors. It is shown that the drive topology can be fed successfully using a matrix converter [19]. The advantage that is offered by this solution is sinusoidal source side current, no use of bulky DC link capacitors, controllable power factor and two-way power flow. The downside of this scheme is the complex system with a large number of bi-directional power semiconductor switches [20]. The output voltage is lower compared to the inverter-based system [21]. An analytical approach was used in this work to advance and study the suggested modulation techniques with additional support by simulation results.

\section{MODELING OF A FIVE-PHASE MATRIX CONVERTER}

The topology of power circuits of three to five-phase matrix converters is represented in Figure 1. The input is a three-phase fixed frequency supply over the grid system $(50 \mathrm{~Hz}$ and $220 \mathrm{~V})$ as well as fixed voltage. The output is n-phase with variable frequencies and voltages. A tiny filter is needed at the input source side and the switches are bi-directional for allowing regenerative operation of the load. The matrix converter is modulated both using a carrier-based Pulse Width Modulation (PWM) [3] and Space Vector PWM (SVPWM) [22].

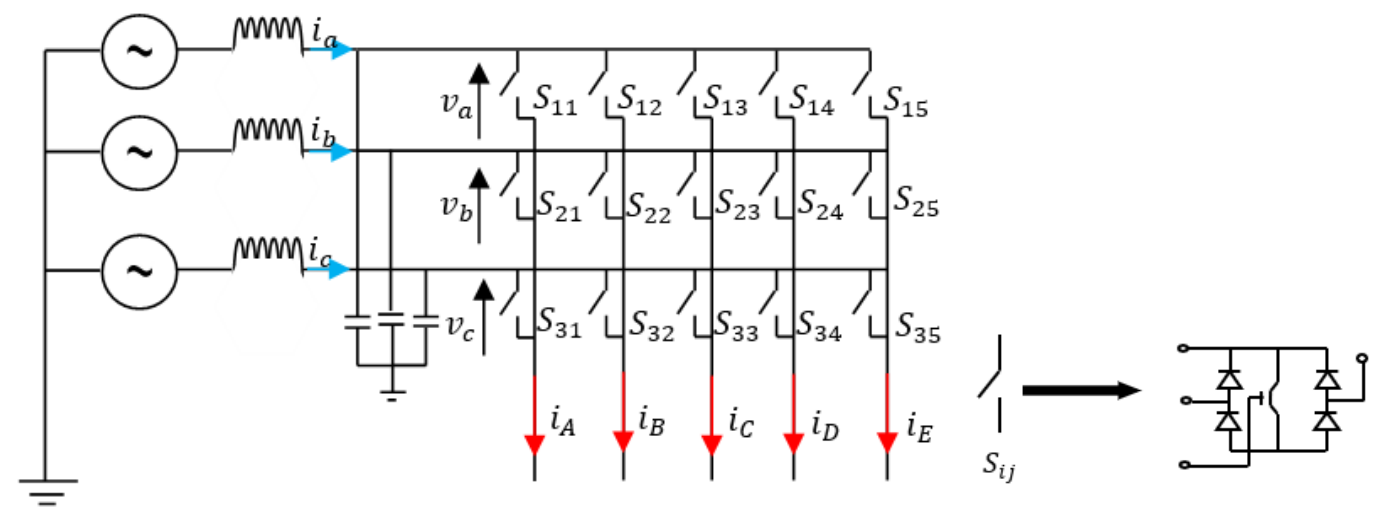

Figure 1. Principle diagram of the Pentaphasées matrix converter

The work presented here of a simple carrier-based PWM scheme is derived in [5]. However, the considered load was a simple R-L load. Furthermore, analytical treatments remained the same as that of [23] as the input side was a three-phase. Nevertheless, the output side increased to five and consequently, the investigation has been changed in order to fit the required number of the output phase. Thus, at the input, a three-phase system is supposed.

$$
\left\{\begin{array}{c}
v_{a}=|V|+\cos (\omega t) \\
v_{b}=|V|+\cos (\omega t-2 \pi / 3) \\
v_{c}=|V|+\cos (\omega t-4 \pi / 3)
\end{array}\right.
$$


Considering that the output voltages of the matrix converter are accompanied by a decoupled frequency from the input voltages, the duty ratios of the switches were consequently calculated. Thus, calculation of the desired five-phase output voltage duty ratios is done with a manner as the output voltage remains unconstrains of the input frequency. To put it differently, the three-phase input voltages could be regarded to be in a stationary reference frame while the five-phase output voltages may be regarded as in a synchronous reference frame hence, in output voltages, the expression of the input frequency is absent. In view of the above-mentioned information, a duty ratio of output phase $\mathrm{j}$ was selected as:

$$
\left\{\begin{array}{c}
\delta_{a i}=k_{i}+\cos (\omega t-\rho) \\
\delta_{b i}=k_{i}+\cos \left(\omega t-\frac{2 \pi}{3}-\rho\right) \\
\delta_{c i}=k_{i}+\cos \left(\omega t-\frac{4 \pi}{3}-\rho\right)
\end{array}\right.
$$

where $\rho$ represents the phase shift at the input side and the input/output voltages are connected as:

$$
\left[\begin{array}{l}
V_{A} \\
V_{B} \\
V_{C} \\
V_{D} \\
V_{E}
\end{array}\right]=\left[\begin{array}{lll}
\delta_{a A} & \delta_{b A} & \delta_{c A} \\
\delta_{a B} & \delta_{b B} & \delta_{c B} \\
\delta_{a C} & \delta_{b C} & \delta_{c C} \\
\delta_{a D} & \delta_{b D} & \delta_{c D} \\
\delta_{a E} & \delta_{b E} & \delta_{c E}
\end{array}\right]\left[\begin{array}{l}
V_{a} \\
V_{b} \\
V_{c}
\end{array}\right]
$$

So, the phase output voltage can be acquired applying the above-mentioned duty ratios as:

$$
\begin{aligned}
& V_{A}=k_{A}|V|[\cos (\omega t) * \cos (\omega t-\rho)+\cos (\omega t-2 \pi / 3) * \cos (\omega t-2 \pi / 3-\rho)+\cos (\omega t- \\
& 4 \pi / 3) * \cos (\omega t-4 \pi / 3-\rho)] \\
& V_{A}=\frac{3}{2} * k_{A}|V| \cos (\rho)
\end{aligned}
$$

The (5), cos $(\rho)$ is used to indicate that the output voltage is impacted by $\rho . \mathrm{k}_{\mathrm{A}}$ is described in equation (18). Therefore, $\mathrm{V}_{\mathrm{A}}$ which is the output voltage is separated from the input frequency depending solely on the amplitude $|\mathrm{V}|$ of the input voltage. $\mathrm{k}_{\mathrm{A}}$ is a reference output voltage time-varying modulating signal for the output phase $A$ including the wanted output frequency $\omega_{01}+\omega_{02}$, with $\omega_{01}$ representing the first fundamental output frequency of the machine-1 which is called also the operating frequency of machine- 1 and $\omega_{02}$ is a second fundamental output frequency named also the operating frequency of machine-2. $\omega_{01}$ is stated as $m_{1}$ while $\omega_{02}$ is stated as $m_{2}$. The five-phase reference output voltages may then be subsequently regarded as:

$$
\begin{aligned}
& \left\{\begin{array}{c}
k_{A 1}=m_{1} \cos \left(\omega_{01} t\right) \\
k_{B 1}=m_{1} \cos \left(\omega_{01} t-2 \pi / 5\right) \\
k_{C 1}=m_{1} \cos \left(\omega_{01} t-4 \pi / 5\right) \\
k_{D 1}=m_{1} \cos \left(\omega_{01} t-6 \pi / 5\right) \\
k_{E 1}=m_{1} \cos \left(\omega_{01} t-8 \pi / 5\right)
\end{array}\right. \\
& \left\{\begin{array}{c}
k_{A 2}=m_{2} \cos \left(\omega_{02} t\right) \\
k_{B 2}=m_{2} \cos \left(\omega_{02} t-2 \pi / 5\right) \\
k_{C 2}=m_{2} \cos \left(\omega_{02} t-4 \pi / 5\right) \\
k_{D 2}=m_{2} \cos \left(\omega_{02} t-6 \pi / 5\right) \\
k_{E 2}=m_{2} \cos \left(\omega_{02} t-8 \pi / 5\right)
\end{array}\right.
\end{aligned}
$$

and:

$$
\left\{\begin{array}{l}
k_{A}=k_{A 1}+k_{A 2} \\
k_{B}=k_{B 1}+k_{B 2} \\
k_{C}=k_{C 1}+k_{C 2} \\
k_{D}=k_{D 1}+k_{D 2} \\
k_{E}=k_{E 1}+k_{E 2}
\end{array}\right.
$$

Therefore, from (5), the output voltages are obtained as: 


$$
\left\{\begin{array}{c}
V_{A}=\left[\frac{3}{2} * k_{A 1}|V| \cos (\rho)\right] \cos \left(\omega_{01} t\right)+\left[\frac{3}{2} * k_{A 2}|V| \cos (\rho)\right] \cos \left(\omega_{02} t\right) \\
V_{B}=\left[\frac{3}{2} * k_{B 1}|V| \cos (\rho)\right] \cos \left(\omega_{01} t-\frac{2 \pi}{5}\right)+\left[\frac{3}{2} * k_{C 2}|V| \cos (\rho)\right] \cos \left(\omega_{02} t-4 \pi / 5\right) \\
V_{C}=\left[\frac{3}{2} * k_{C 1}|V| \cos (\rho)\right] \cos \left(\omega_{01} t-\frac{4 \pi}{5}\right)+\left[\frac{3}{2} * k_{E 2}|V| \cos (\rho)\right] \cos \left(\omega_{02} t-8 \pi / 5\right) \\
V_{D}=\left[\frac{3}{2} * k_{D 1}|V| \cos (\rho)\right] \cos \left(\omega_{01} t-\frac{6 \pi}{5}\right)+\left[\frac{3}{2} * k_{B 2}|V| \cos (\rho)\right] \cos \left(\omega_{02} t-2 \pi / 5\right) \\
V_{E}=\left[\frac{3}{2} * k_{E 1}|V| \cos (\rho)\right] \cos \left(\omega_{01} t-\frac{8 \pi}{5}\right)+\left[\frac{3}{2} * k_{D 2}|V| \cos (\rho)\right] \cos \left(\omega_{02} t-6 \pi / 5\right)
\end{array}\right.
$$

The discussion on the addition of the common-mode voltage and subsequent enhancement of the modulation index is presented in [4].

\section{FIVE-PHASE SERIES-CONNECTED TWO MOTOR DRIVE}

Basic topology of five-phase series-connected two-motor drive systems is represented in the Figure 1. The variable frequency (VF) source is supplying a five-phase IM (Motor 1) whose stator windings are connected to another five-phase IM (Motor 2) through appropriate phase transposition. The rotors of the two machines are independent and are connected to different mechanical loads [24].

Consequently, of the phase transposition that is represented in Figure 2, the inverter phase voltages were connected to separate machine phase voltages by:

$$
\left\{\begin{array}{l}
v_{A}=v_{a s 1}+v_{a s 2} \\
v_{B}=v_{b s 1}+v_{c s 2} \\
v_{C}=v_{c s 1}+v_{e s 2} \\
v_{D}=v_{d s 1}+v_{b s 2} \\
v_{E}=v_{e s 1}+v_{d s 2}
\end{array}\right.
$$

Generally, although both machines are of a five-phase, they might be different and as a consequence, they might have different parameters. The index ' 1 ' stands for the $1^{\text {st }}$ IM that is immediately connected to a five-phase inverter while the index ' 2 ' denotes the $2^{\text {nd }}$ IM which is connected past the $1^{\text {st }}$ machine throughout the phase transposition.

Thus, the voltage equation of the whole system is scripted in a compact matrix form as:

$\underline{v}=\underline{R} * \underline{i}+\frac{d(\underline{L} * \underline{i})}{d t}$

Where the $15^{\text {th }}$ order of the system is used and

$$
\begin{aligned}
& \underline{v}=\left[\begin{array}{c}
\underline{v}^{i n v} \\
\underline{0} \\
\underline{0}
\end{array}\right], \underline{i}=\left[\begin{array}{l}
\underline{\underline{i}}^{i n v} \\
\underline{i}_{r 1} \\
\underline{i}_{r 2}
\end{array}\right] ; \underline{v}^{i n v}=\left[\begin{array}{llll}
v_{A} v_{B} v_{C} & v_{D} & v_{E}
\end{array}\right]^{T} ; \underline{i}^{i n v}=\left[\begin{array}{lll}
i_{A} i_{B} i_{C} & i_{D} & i_{E}
\end{array}\right]^{T} ; \\
& \underline{i}_{r 1}=\left[\underline{i}_{a r 1} i_{b r 1} i_{c r 1} i_{d r 1} i_{e r 1}\right]^{T} ; \underline{i}_{r 2}=\left[\begin{array}{lll}
i_{a r 2} i_{b r 2} i_{c r 2} i_{d r 2} & i_{e r 2}
\end{array}\right]^{T}
\end{aligned}
$$

The decoupling transformation was applied to ease the phase-domain model. [25], [26] has given Clark's decoupling matrix in power-invariant transformation.

$$
[c]=\sqrt{\frac{2}{5}}\left[\begin{array}{ccccc}
1 & \cos (\alpha) & \cos (2 \alpha) & \cos (3 \alpha) & \cos (4 \alpha) \\
0 & \sin (\alpha) & \sin (2 \alpha) & \sin (3 \alpha) & \sin (4 \alpha) \\
1 & \cos (2 \alpha) & \cos (4 \alpha) & \cos (6 \alpha) & \cos (8 \alpha) \\
0 & \sin (2 \alpha) & \sin (4 \alpha) & \sin (6 \alpha) & \sin (8 \alpha) \\
\sqrt{1 / 2} & \sqrt{1 / 2} & \sqrt{1 / 2} & \sqrt{1 / 2} & \sqrt{1 / 2}
\end{array}\right]
$$

By excluding the $x-y$, zero-sequence equation about the inverter as well as the zero-sequence equation for rotor windings, over the two five-phase series-connected machines, the complete d-q model in the stationary reference frame is written in the elaborated form as: 
$\left\{\begin{array}{l}V_{d}^{i n v}=R_{s 1} i_{d}^{i n v}+L_{s 1} \frac{d i_{d}^{i n v}}{d t}+L_{m 1} \frac{d i_{d r 1}}{d t}+R_{s 2} i_{d}^{i n v}+L_{s 2} \frac{d i_{d}^{i n v}}{d t} \\ V_{q}^{i n v}=R_{s 1} i_{q}^{i n v}+L_{s 1} \frac{d i_{q}^{i n v}}{d t}+L_{m 1} \frac{d i_{q r 1}}{d t}+R_{s 2} i_{q}^{i n v}+L_{s 2} \frac{d i_{q}^{i n v}}{d t} \\ V_{x}^{i n v}=R_{s 1} i_{x}^{i n v}+L_{s 1} \frac{d i_{x}^{i n v}}{d t}+R_{s 2} i_{x}^{i n v}+L_{s 2} \frac{d i_{x}^{i n v}}{d t}+L_{m 2} \frac{d i_{\alpha r 2}}{d t} \\ V_{y}^{i n v}=R_{s 1} i_{y}^{i n v}+L_{s 1} \frac{d i_{y}^{i n v}}{d t}+R_{s 2} i_{y}^{i n v}+L_{s 2} \frac{d i_{y}^{i n v}}{d t}+L_{m 2} \frac{d i_{\beta r 2}}{d t}\end{array}\right.$

Corresponding rotor equations are:

$$
\left\{\begin{array}{l}
0=R_{r 1} i_{d r 1}+L_{m 1} \frac{d i_{d}^{i n v}}{d t}+\left(L_{r 1}+L_{m 1}\right) \frac{d i_{d r 1}}{d t}+\omega_{1}\left(L_{m 1} i_{q}^{i n v}+\left(L_{r 1}+L_{m 1}\right) i_{q r 1}\right) \\
0=R_{r 1} i_{q r 1}+L_{m 1} \frac{d i_{q}^{i q v}}{d t}+\left(L_{r 1}+L_{m 1}\right) \frac{d i_{q r 1}}{d t}-\omega_{1}\left(L_{m 1} i_{d}^{i n v}+\left(L_{r 1}+L_{m 1}\right) i_{d r 1}\right) \\
0=R_{r 2} i_{d r 2}+L_{m 2} \frac{d i_{x}^{i n v}}{d t}+\left(L_{r 2}+L_{m 2}\right) \frac{d i_{d r 2}}{d t}+\omega_{2}\left(L_{m 2} i_{y}^{i n v}+\left(L_{r 2}+L_{m 2}\right) i_{q r 2}\right) \\
0=R_{r 2} i_{q r 2}+L_{m 2} \frac{d i_{y}^{i n v}}{d t}+\left(L_{r 2}+L_{m 2}\right) \frac{d i_{q r 2}}{d t}-\omega_{2}\left(L_{m 2} i_{x}^{i n v}+\left(L_{r 2}+L_{m 2}\right) i_{d r 2}\right)
\end{array}\right.
$$

The electromagnetic torques are evaluated as:

$\left\{\begin{array}{l}T_{r 1}=P_{1} L_{m 1}\left(i_{d r 1} i_{q}-i_{d} i_{q r 1}\right) \\ T_{r 2}=P_{2} L_{m 2}\left(i_{d r 2} i_{y}-i_{x} i_{q r 2}\right)\end{array}\right.$

The mechanical equation of the two machines is described as:

$$
\left\{\begin{array}{l}
J_{m 1} \frac{d}{d t} \Omega_{1}=T_{r 1}-T_{L 1}-f_{m 1} \Omega_{1} \\
J_{m 2} \frac{d}{d t} \Omega_{2}=T_{r 2}-T_{L 2}-f_{m 2} \Omega_{2}
\end{array}\right.
$$

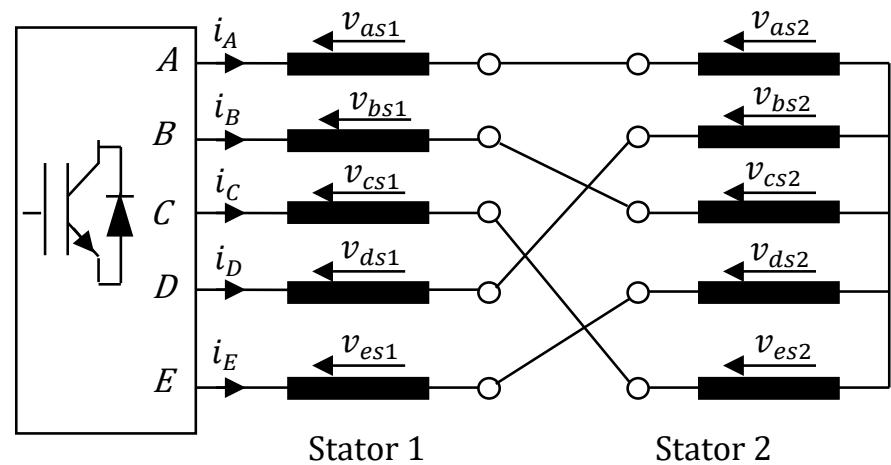

Figure 2. Representation of two five-phase IM in series with transposed stator phases

\section{VECTOR CONTROL OF THE TWO-MOTOR DRIVE}

As stated by (13)-(16), the phase transposition places the stator $\mathrm{d}-\mathrm{q}$ axis windings of the $2^{\text {nd }}$ machine in series connected with the $\mathrm{x}-\mathrm{y}$ windings of the $1^{\text {st }}$ machine (for example into the $\mathrm{x}-\mathrm{y}$ subspace of the inverter). In addition, using standard indirect method of Rotor Flux Oriented (RFO) control, the independent vector control of the two machines can be achieved. For the indirect RFO controller for the two machines, it is of a similar structure in addition to an asymmetrical six-phase or three-phase machines [20]. Furthermore, as shown in Figure 3, only one difference is noted which is at the output, five instead of threephase current references are established. The two indirect RFO controllers that function parallelly gave at the output phase current references $(\mathrm{k}=\sqrt{2 / 5}$ of the two machines with references for $\mathrm{x}-\mathrm{y}$ stator current components that are zero for both machines as given by Figure 3. 


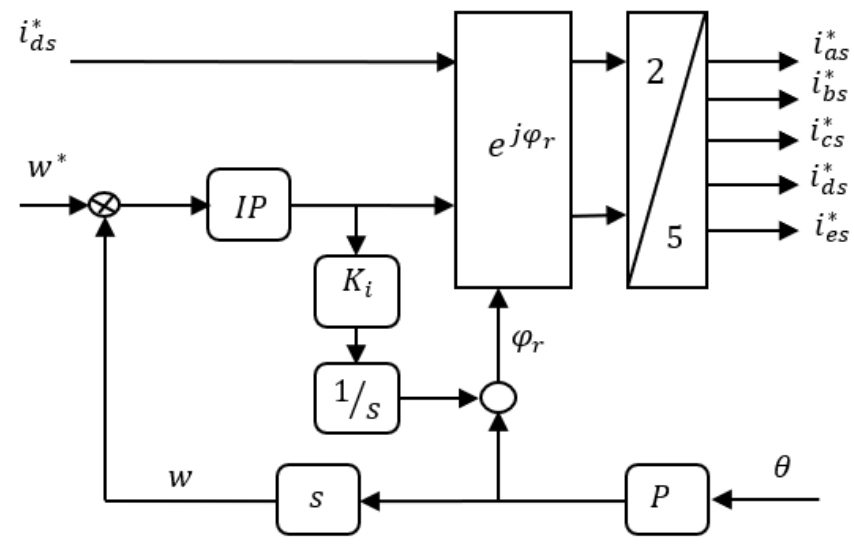

Figure 3. Indirect RFO controller for a five-phase induction machine $\left(\mathrm{k}_{1}=\frac{1}{\mathrm{~T}_{\mathrm{r}} \mathrm{i}_{\mathrm{ds}}^{*}}\right)$

$$
\begin{aligned}
& \left\{\begin{array}{c}
i_{a s 1}^{*}=k\left(i_{d s 1}^{*} \cos \varphi_{r 1}-i_{q s 1}^{*} \sin \varphi_{r 1}\right) \\
i_{b s 1}^{*}=k\left(i_{d s 1}^{*} \cos \left(\varphi_{r 1}-\alpha\right)-i_{q s 1}^{*} \sin \left(\varphi_{r 1}-\alpha\right)\right) \\
i_{c s 1}^{*}=k\left(i_{d s 1}^{*} \cos \left(\varphi_{r 1}-2 \alpha\right)-i_{q s 1}^{*} \sin \left(\varphi_{r 1}-2 \alpha\right)\right) \\
i_{d s 1}^{*}=k\left(i_{d s 1}^{*} \cos \left(\varphi_{r 1}-3 \alpha\right)-i_{q s 1}^{*} \sin \left(\varphi_{r 1}-3 \alpha\right)\right) \\
i_{e s 1}^{*}=k\left(i_{d s 1}^{*} \cos \left(\varphi_{r 1}-4 \alpha\right)-i_{q s 1}^{*} \sin \left(\varphi_{r 1}-4 \alpha\right)\right)
\end{array}\right. \\
& \left\{\begin{array}{c}
i_{a s 2}^{*}=k\left(i_{d s 2}^{*} \cos \varphi_{r 2}-i_{q s 2}^{*} \sin \varphi_{r 2}\right) \\
i_{b s 2}^{*}=k\left(i_{d s 2}^{*} \cos \left(\varphi_{r 2}-\alpha\right)-i_{q s 2}^{*} \sin \left(\varphi_{r 2}-\alpha\right)\right) \\
i_{c s 2}^{*}=k\left(i_{d s 2}^{*} \cos \left(\varphi_{r 2}-2 \alpha\right)-i_{q s 2}^{*} \sin \left(\varphi_{r 2}-2 \alpha\right)\right) \\
i_{d s 2}^{*}=k\left(i_{d s 2}^{*} \cos \left(\varphi_{r 2}-3 \alpha\right)-i_{q s 2}^{*} \sin \left(\varphi_{r 2}-3 \alpha\right)\right) \\
i_{e s 2}^{*}=k\left(i_{d s 2}^{*} \cos \left(\varphi_{r 2}-4 \alpha\right)-i_{q s 2}^{*} \sin \left(\varphi_{r 2}-4 \alpha\right)\right)
\end{array}\right.
\end{aligned}
$$

For the establishment of the overall inverter current references, the currents in (17) and (18) are summarized and the series connections with phase transposition are presented in Figure 3.

$$
\left\{\begin{array}{l}
i_{A}^{*}=i_{a s 1}^{*}+i_{a s 2}^{*} \\
i_{B}^{*}=i_{b s 1}^{*}+i_{b s 2}^{*} \\
i_{c}^{*}=i_{c s 1}^{*}+i_{c s 2}^{*} \\
i_{d}^{*}=i_{d s 1}^{*}+i_{d s 2}^{*} \\
i_{E}^{*}=i_{e s 1}^{*}+i_{e s 2}^{*}
\end{array}\right.
$$

In the frame of the stationary reference, the closed-loop phase current control is at the end used to force the proper inverter output currents of (2) in order to trace the reference currents of (19). Supposing that the idealistic current control is applied, one has the equivalence of the reference inverter currents (19) with the proper inverter currents (2) therefore, machine currents are connected with reference machine currents of (17) and (18) by:

$$
\left\{\begin{array}{l}
i_{a s 1}=i_{a s 2}=i_{a s 1}^{*}+i_{a s 2}^{*} \\
i_{b s 1}=i_{c s 2}=i_{b s 1}^{*}+i_{b s 2}^{*} \\
i_{c s 1}=i_{e s 2}=i_{c s 1}^{*}+i_{c s 2}^{*} \\
i_{d s 1}=i_{b s 2}=i_{d s 1}^{*}+i_{d s 2}^{*} \\
i_{e s 1}=i_{d s 2}=i_{e s 1}^{*}+i_{e s 2}^{*}
\end{array}\right.
$$

In consideration of the right-hand part of (19) that includes in a stable-state operation two sets of sinusoidal currents, generally distinct frequencies and amplitudes were added in accordance with the phase transposition that is shown in Figure 3. Following (19), each of the five-phases of any of the two-machines 
carries at the same time two sinusoidal current components. Furthermore, one directs the flux/torque producing $(\alpha-\beta)$ components and the other is as a result of the other machine in series determining parasitic $(\mathrm{x}-\mathrm{y})$ current components.

\section{SIMULATION RESULTS}

MATLAB/Simulink for the complete drive system was used for the developement of the simulation model. The three-phase grid supply was supposed as $50 \mathrm{~Hz}$ and $400 \mathrm{~V}$ rms phase voltage and since the twomotor drive was taken into account, the double voltage was assumed. For the $1^{\text {st }}$ machine, the five-phase reference voltage was selected while for the $2^{\text {nd }}$ machine, a different set of five-phase reference was chosen. The five-phase modulating signals were developed by including the two five-phase references as reported in the transposition rule (7).

The simulation condition is presented as;

Motor-1 working at $1500 \mathrm{rpm}$ rated speed (reference frequency of $50 \mathrm{~Hz}$ ) and Motor-2 working at half of rated speed of $750 \mathrm{rpm}$ and a reference frequency of $50 \mathrm{~Hz}$.

In the initial trial, the $1^{\text {st }}$ machine operates at $1500 \mathrm{rpm}$ then at $-1500 \mathrm{rpm}$ at $\mathrm{t}=0.9 \mathrm{~s}$ and the second machine was running at $750 \mathrm{rpm}$ of the speed reference. The load torque that were applied to the first and second machines was $100 \%$ of the rated torque at respectively $t_{1}=[1-3] \mathrm{s}$ and $\mathrm{t}_{2}=[1.5-3.5] \mathrm{s}$.

In the third test, the first machine was running at $1500 \mathrm{rpm}$ then at $-1500 \mathrm{rpm}$ at $\mathrm{t}=0.9 \mathrm{~s}$ and the second machine speed reference was of $750 \mathrm{rpm}$. The load torque applied to the first machine was $100 \%$ of the rated torque at $t_{1}=[1-3] \mathrm{s}$. In addition, the first machine was running at $1500 \mathrm{rpm}$ and for the second machine, it was $750 \mathrm{rpm}$, then $-750 \mathrm{rpm}$ at $t_{2}=[1.5-3.5] \mathrm{s}$ the speed reference of the $2^{\text {nd }}$ motor. The load torque applied to the first and second machines is $100 \%$ of the rated torque. It is evident from Figures (4, 5, 6 and 7) and Figures $\left(8,9,10,11,12\right.$ and 13) that the loading step of the $2^{\text {nd }}$ motor does not generate any disturbance in the $1^{\text {st }}$ motor's speed and torque references traces.

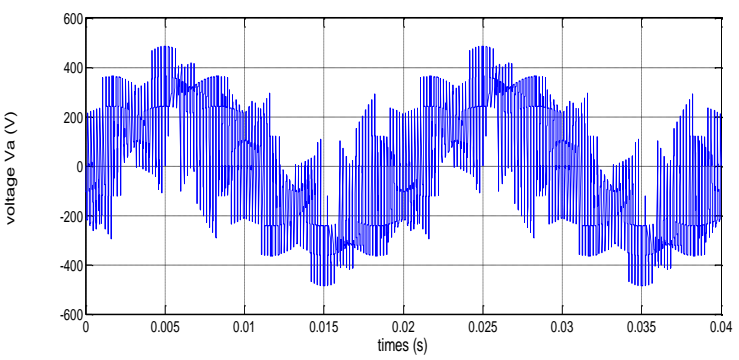

Figure 4. Output voltage Va (V)

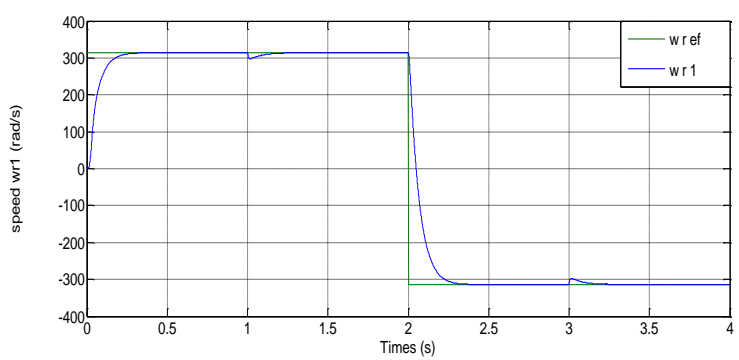

Figure 6. Speeds of the first machine Vs its reference value

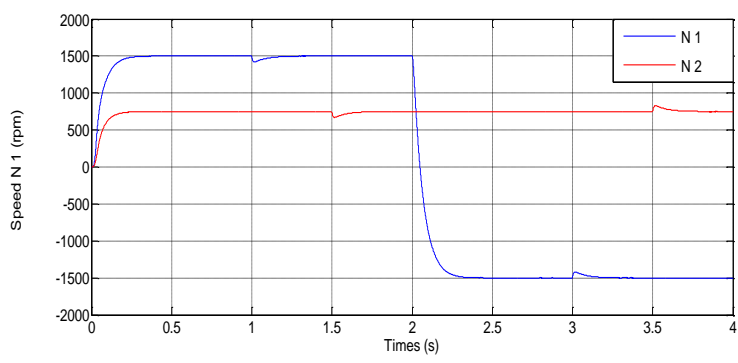

Figure 5. Speeds of the first and second machine

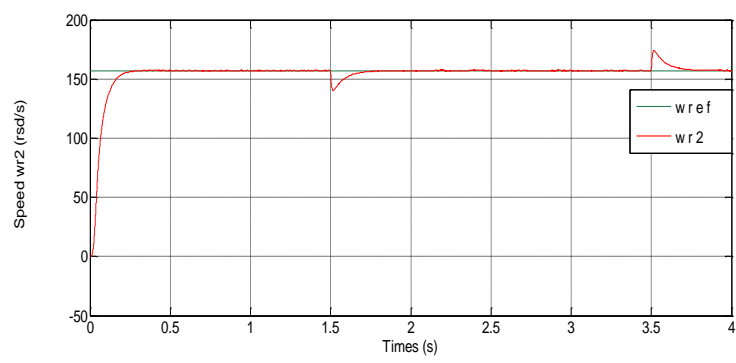

Figure 7. Speeds of the second machine Vs its reference value 


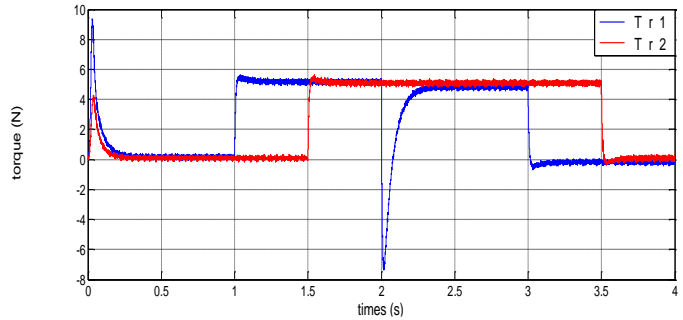

Figure 8. Torques of the first and second machines.

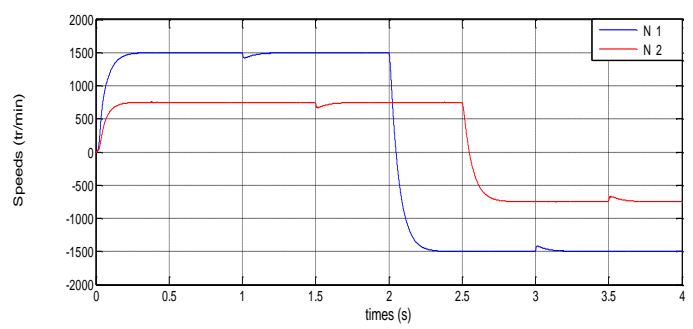

Figure 10. Speeds of the first and second machine

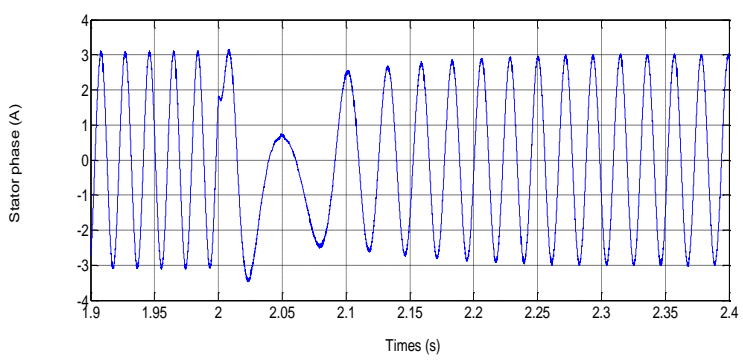

Figure 12. Currentis one phase of the firest machines

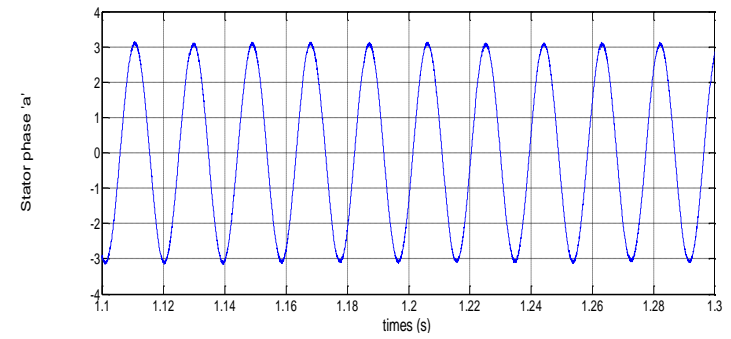

Figure 9. Currents is one phase of the first machines

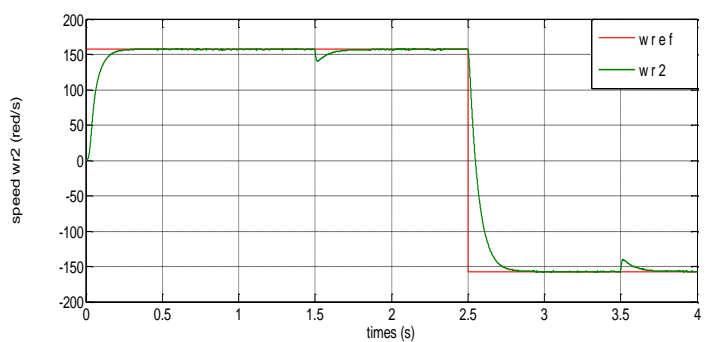

Figure 11. Speeds of the second machine Vs its reference value

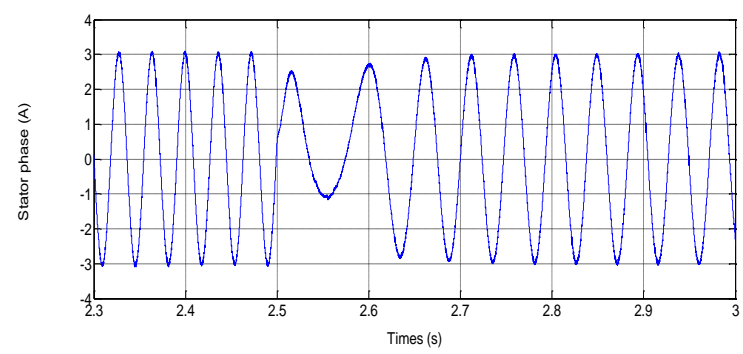

Figure 13. Currentis one phase of the second machines

\section{CONCLUSIONS}

Three to five-phases matrix converters based five-phase series-connected two-motor drive structure was presented in this paper. The carrier-based PWM techniques were used for the control of the matrix converter. The matrix converter successfully drives the two five-phase series-connected induction machines. This solution has an advantage of a higher power factor and sinusoidal source side current. We have obtained a completely decoupled control by the independent vector control, which allowed decoupling the flux control and the torque for the two machines, which leads to control several machines in series that can have polyphase machines of different types

\section{SIMULATION PARAMETERS}

\begin{tabular}{lccc}
\hline \multicolumn{1}{c}{ Parameters } & symbol & Values & Units \\
\hline Stator resistance & $R_{S}$ & 6.3 & $\Omega$ \\
Rotor resistance & $R_{r}$ & 10 & $\Omega$ \\
Stator leakage inductance & $L_{l s}$ & 0.46 & $\mathrm{mH}$ \\
Rotor leakage inductance & $L_{l r}$ & 0.46 & $\mathrm{mH}$ \\
Mutual inductance & $M$ & 0.42 & $\mathrm{mH}$ \\
Stator rated Frequency & $f_{S}$ & 50 & $\mathrm{~Hz}$ \\
Moment of Inertia & $J_{m}$ & 0.01 & $\mathrm{Kg} \cdot \mathrm{m}^{2}$ \\
Number of Poles & $P$ & 2 & $\mathrm{Nm}$ \\
Rated Torque & $T_{r}$ & 5 & \\
\hline
\end{tabular}




\section{REFERENCES}

[1] Yahya Ahmed Alamri, Nik Rumzi Nik Idris, Ibrahim Mohd. Alsofyani, Tole Sutikno, "Improved Stator Flux Estimation for Direct Torque Control of Induction Motor Drives," International Journal of Power Electronics and Drive Systems (IJPEDS), vol. 7, no. 4, pp. 1049-1060, 2016, DOI: 10.11591/ijpeds.v7.i4.pp1049-1060.

[2] S. Williamson and S. Smith, "Pulsating torque and losses in multiphase induction machines," Conference Record of the 2001 IEEE Industry Applications Conference. 36th IAS Annual Meeting (Cat. No.01CH37248), 2001, pp. 11551162 vol.2, DOI: 10.1109/IAS.2001.955635.

[3] M.R. Arahal and M.J. Duran, "PI tuning of Five-phase drives with third harmonic injection", Control Engineering Practice, Vol. 17, no. 7, pp. 787-797, July 2009, DOI: 10.1016/j.conengprac.2008.12.005.

[4] D. Dujic, M. Jones and E. Levi, "Analysis of Output Current Ripple rms in Multiphase Drives Using Space Vector Approach," in IEEE Transactions on Power Electronics, vol. 24, no. 8, pp. 1926-1938, Aug. 2009, DOI: 10.1109/TPEL.2009.2017746.

[5] J.M. Apsley, S. Williamsons, A.C. Smith and M. Barnes, "Induction motor performance as a function of phase number," Proc. Int. Electr. Eng.-Electr. Power Appl., vol. 153, no. 6, Nov. 2006, pp. 898-904, DOI:10.1049/ipepa:20060091.

[6] H. A. Toliyat, T. A. Lipo and J. C. White, "Analysis of a concentrated winding induction machine for adjustable speed drive applications. II. Motor design and performance," in IEEE Transactions on Energy Conversion, vol. 6, no. 4, pp. 684-692, Dec. 1991, DOI: $10.1109 / 60.103642$.

[7] H. A. Toliyat, S. P. Waikar and T. A. Lipo, "Analysis and simulation of five-phase synchronous reluctance machines including third harmonic of airgap MMF," in IEEE Transactions on Industry Applications, vol. 34, no. 2, pp. 332-339, March-April 1998, DOI: 10.1109/28.663476.

[8] N. Bianchi, S. Bolognani and M. Dai Pre, "Strategies for the Fault-Tolerant Current Control of a Five-Phase Permanent-Magnet Motor," in IEEE Transactions on Industry Applications, vol. 43, no. 4, pp. 960-970, July-aug. 2007, DOI: 10.1109/TIA.2007.900445.

[9] L. Zheng, J. E. Fletchert and B. W. Williams, "Current Optimization for a Multi-Phase Machine under an Open Circuit Phase Fault Condition," 2006 3rd IET International Conference on Power Electronics, Machines and Drives - PEMD 2006, 2006, pp. 414-419.

[10] Rachid Taleb, M'hamed Helaimi, Djilali Benyoucef and Zinelaabidine Boudjema, "Genetic Algorithm Application in Asymmetrical 9-Level Inverter", International Journal of Power Electronics and Drive System (IJPEDS), Vol. 7, No. 2, pp. 521-530, June 2016, DOI: 10.11591/ijpeds.v7.i2.pp521-530.

[11] M. J. Duran, F. Salas and M. R. Arahal, "Bifurcation Analysis of Five-Phase Induction Motor Drives With Third Harmonic Injection," in IEEE Transactions on Industrial Electronics, vol. 55, no. 5, pp. 2006-2014, May 2008, DOI: 10.1109/TIE.2008.918470.

[12] N. Lavanya and M. Venu Gopala Rao, "Control of Indirect Matrix Converter by Using Improved SVM Method," International Journal of Power Electronics and Drive System (IJPEDS), Vol. 6, No. 2, pp. 370-375, June 2015, DOI: 10.11591/ijpeds.v6.i2.pp370-375.

[13] D. Sri Vidhya, T. Venkatesan," A Review on Performance Analysis of Matrix Converter Fed AC Motor Drive," International Journal of Power Electronics and Drive System (IJPEDS), vol. 7, no. 1, pp. 85-93, March 2016, DOI: 10.11591/ijpeds.v7.i1.pp85-93.

[14] E. Levi, "Multiphase Electric Machines for Variable-Speed Applications," in IEEE Transactions on Industrial Electronics, vol. 55, no. 5, pp. 1893-1909, May 2008, DOI: 10.1109/TIE.2008.918488.

[15] M. Jones, E. Levi and S. N. Vukosavic, "Independent Control of Two Five-Phase Induction Machines Connected in Parallel to a Single Inverter Supply," IECON 2006 - 32nd Annual Conference on IEEE Industrial Electronics, 2006, pp. 1257-1262, DOI: 10.1109/IECON.2006.348152.

[16] E. Levi, A. Iqbal, S. N. Vukosavic and H. A. Toliyat, "Modeling and control of a five-phase series-connected twomotor drive," IECON'03. 29th Annual Conference of the IEEE Industrial Electronics Society (IEEE Cat. No.03CH37468), 2003, pp. 208-213 vol.1, DOI: 10.1109/IECON.2003.1279981.

[17] E. Levi, M. Jones, S.N. Vukosavic, H.A. Toliyat, "A five-phase twomachine vector controlled induction motor drive supplied from a single inverter", European Power Electronics and Drives, vol. 14, no. 3, pp. 38-48, 2004, DOI: $10.1080 / 09398368.2004 .11463564$.

[18] E. Levi, M. Jones, A. Iqbal, S. N. Vukosavic and H. A. Toliyat, "Induction Machine/Syn-Rel Two-Motor FivePhase Series-Connected Drive," in IEEE Transactions on Energy Conversion, vol. 22, no. 2, pp. 281-289, June 2007, DOI: 10.1109/TEC.2006.875457.

[19] P. C. Loh, R. J. Rong, F. Blaabjerg and P. Wang, "Digital carrier modulation and sampling issues of matrix converters," 2008 Twenty-Third Annual IEEE Applied Power Electronics Conference and Exposition, 2008, pp. 231-237, DOI: 10.1109/APEC.2008.4522727.

[20] M. Benali Youcef, A. Djahbar and B. Mazari "Modeling and control the set of matrix converter-two five-phase wheel motors (2 pmsm) for driving an electric traction system" Journal of Electrical Engineering (JEE), 2018.

[21] L. Yaohua, L. Jingyu, M. Jian and Y. Qiang, "A Simplified voltage vector selection strategy for direct torque ontrol," TELKOMNIKA Telecommunication, Computing, Electronics and Control, vol. 9, pp. 539-546, December 2011, DOI: 10.12928/telkomnika.v9i3.746.

[22] Thirumoorthi, P and T D, Raheni, "Adaptive Method for Power Quality Improvement through Minimization of Harmonics Using Artificial Intelligence," International Journal of Power Electronics and Drive Systems (IJPEDS), Vol. 8, No. 1, pp. 470-482, 2017, DOI: 10.11591/ijpeds.v8.i1.pp470-482. 
[23] L. Rmili, M. Hamouda, S. Rahmani and K. Al-Haddad, "Advanced topologies of multilevel matrix converter," 16th International Conference on Sciences and Techniques of Automatic Control and Computer Engineering (STA), 2015, pp. 599-604, DOI: 10.1109/STA.2015.7505221.

[24] M. J. Duran, F. J. Barrero, S. L. Toral and E. Levi, "Multi-Dimensional Space Vector Pulse Width Modulation Scheme for Five-Phase Series-Connected Two-Motor Drives," 2007 IEEE International Electric Machines \& Drives Conference, 2007, pp. 1208-1214, DOI: 10.1109/IEMDC.2007.383602.

[25] E. Levi, A. Iqbal, S. N. Vukosavic and H. A. Toliyat, "Modeling and control of a five-phase series-connected twomotor drive," IECON'03. 29th Annual Conference of the IEEE Industrial Electronics Society (IEEE Cat. No.03CH37468), 2003, pp. 208-213 vol.1, DOI: 10.1109/IECON.2003.1279981.

[26] E. Levi, M. Jones, S. N. Vukosavic and H. A. Toliyat, "Steady State Modeling of Series-Connected Five-Phase and Six-Phase Two-Motor Drives," Conference Record of the 2006 IEEE Industry Applications Conference Forty-First IAS Annual Meeting, 2006, pp. 415-422, DOI: 10.1109/IAS.2006.256555.

\section{BIOGRAPHIES OF AUTHORS}

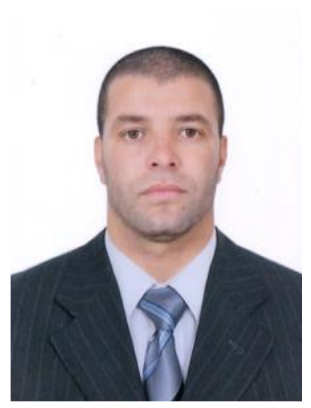

Mohamed Nekkaz was born in Chlef, Algeria, inFebruary 1986, He received the Engineer and Masterdegrees in electrical engineering from the university hassiba ben bouali of Chlef, Algeria, in 2009 and 2012, respectively. He is a Ph.D. student in electrical engineering at university hassiba ben bouali of Chlef since 2013. His scientific work is related to electrical machines, and drives and Power Electronics. His present research interests include multi machine drives, degraded mode, matrix converter and power quality.

Email: Nekkaz_mohamed@yahoo.fr

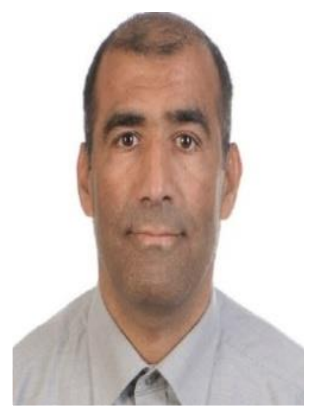

Professor Abdelkader Djahbar was born in Chlef, Algeria, in February 1970. He received the Eng. and M.Sc. degrees in electrical engineering from the National Polytechnic school of Algiers, Algeria, in 1995 and 1998, respectively, and the Ph.D. degree in electrical engineering from the Mohamed Boudiaf University of Science and Technology of Oran (USTO), Algeria, in 2008 and the Habilitation to lead Researches in 2012 at the USTO University, Algeria. In December 2002, he joined the electrical engineering department of Hassiba Ben Bouali Univesity of Chlef, Algeria. Since August 2012, he is Associate Professor in the samedepartment. He is associate researcher in the LMOPS laboratory of the Université de Lorraine and Centrale Supélec since April 2014 and researcher at the LGEER laboratory of UHBC since 2013. His scientific work is related to electrical machines and drives and Power Electronics. His present research interests include multi machine drives, matrix converter and power quality. Email: a djahbar@yahoo.fr

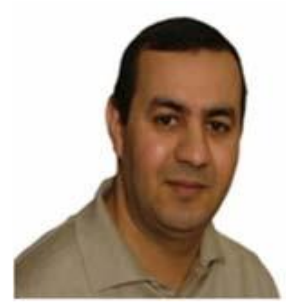

Professor Rachid Taleb received the M.S. degree in electrical engineering from the Hassiba Benbouali University, Chlef, Algeria, in 2004 and the Ph.D. degree in electrical engineering from the Djillali Liabes University, Sidi Bel-Abbes, Algeria, in 2011. Currently he is a professor with the Department of Electrical Engineering, Hassiba Benbouali University. He is a team leader in the LGEER Laboratory (Laboratoire Génie Electrique et Energies Renouvelables). His research interest includes intelligent control, heuristic optimization, control theory of converters and converters for renewable energy sources.

E-mail: rac.taleb@gmail.com 